\title{
İşkolik Davranışlar, Algılanan Katkı ve Yaşam Doyumu İlişkisinde İşte Kendini Yetiştirmenin Aracı Etkisi
}

\author{
Recep ÖZSÜRÜNÇ ${ }^{1}$ \\ Dr. Öğr. Üye. Ömer Erdem KOÇAK ${ }^{2}$
}

\begin{abstract}
$\ddot{O Z Z}$
Bu çalışmanın amacı, işsolik davranışların hem kişinin yaşam doyumu hem de kendi çevrelerine ne derece katkı yaptıklarına dair inançları arasındaki ilişkilerde, iş̧te kendini yetiştirmenin aracı rolünü inceleyerek, işsolik davranışların bireyin iş ve iş dışı hayatına nasıl etki edebileceğine ışık tutmaktır. Kolayda örnekleme yöntemi kullanilarak ulaşılan 259 (n=189) kişsiden toplanan verilerle analizler gerçekleştirilmiştir. Analizler için yapısal eşitlik modellemesi kullanılmış, aracı değiş̧ken etkisi için bootstrap yöntemi kullanılmıştır. Çalışmada elde edilen sonuçlara göre, iş̧te kendini yetiş̧tirme değişkeni algılanan katkı ve yaşam doyumu değişkenleri için aracı değiş̧en etkisi göstermektedir. Bulguların daha önce elde edilmemis sonuçlar ortaya koymasının literatüre katkı sağlayacağı düşünülmektedir.
\end{abstract}

Anahtar Kelimeler: Yaşam Doyumu, İşsolik Davranışlar, İşte Kendini Yetiştirme, Algılanan Katkı

The Mediating Effect of Thriving at Work Between Workaholic Behaviors, Perceived Contribution and Life Satisfaction

Abstract

The aim of this study is to investigate whether thriving at work plays a mediator role in two relationships between workaholic behaviors and (i)perceived contribution to organization, and (ii)life satisfaction in order to shed light on how it can influence employees both job and off-job life. Using convenience sampling method, data was collected from 259 (n=189) participants. Results of the structural equation modelling with bootstrap method indicated that thriving at work is an underlying mechanism for the effect of workaholic behaviors to both life satisfaction and perceived contribution to organization. These findings revealed that workaholic behaviors are not only those result negative outcomes but also have a bright side for those feel vitality and learning.

Keywords: Life Satisfaction, Thriving at Work, Perceived Contribution to Organization

\footnotetext{
${ }^{1}$ İstanbul Üniversitesi, Sayısal Yöntemler Doktora Öğrencisi, rozsurunc@medipol.edu.tr, https://orcid.org/0000-0001-65997823

2 İstanbul Medipol Üniversitesi, İşletme (İngilizce) Bölümü Öğretim Üyesi, oekocak@medipol.edu.tr, https://orcid.org/00000002-4649-2042

Makale Geliş Tarihi: 20.05.2021, Makale Kabul Tarihi: 28.06.2021
}

ARAŞTIRMA MAKALESİ (Research Article)

* Bu makale intihal programında taranmış ve en az iki hakem incelemesinden geçmiştir. (This article has been scanned via a plagiarism software and reviewed by at least two referees). 


\section{Giriş}

İnsanların yaşamla ilişkileri ve yaşamla ilgili amaçlarının ne olduğu sorusu, ilk insandan beridir üzerinde tartışılan bir konudur. Aristo'nun izinden giden Farabi'ye göre insanın en yüce amacı mutluluktur (Tokat, 2006). Mutluluk araştırmalarında, araştırmacılar mutluluğu öznel esenlik durumu olarak kavramsallaştırmışlardır (Deiner, 2000; Diener vd., 1998). Yaşam doyumu, mutluluk ile eş anlamlı kavramlar olmasa bile, kişileri neyin mutlu ettiğini anlamada önemli bir rol oynar (Erdoğan vd., 2012). Yaşam doyumu ile ilgili olarak yapılan çalışmalar, özellikle iş hayatı ekseninde, yaşam doyumunun belirleyicilerini daha derinlemesine araştırma gerekliliğini ortaya koymaktadır (Hochschild, 1997; Peterson, vd., 2005; Erdoğan vd., 2012).

Özellikle Türkiye gibi toplulukçu kültüre yakın olan ülkelerde örgüt içerisindeki üyelerin diğer arkadaşlarına yardım etmesi ve bu anlamda faydalı olmasının, bireyin kimliği açısından önemli olduğu bilinmektedir (Singelis, 1995; Singelis, 1999). Kimliğin önemli bir unsuru olan iş kimliğinin, kişinin çevresine yaptığını düşündüğü katkının ve kişinin mutluluğu açısından önemli olduğu görülmüştür (Grant, 2014). Bununla birlikte son yıllarda iş hayatındaki rekabet baskısının çalışanlar üzerindeki olumsuz etkilerinden birisinin de işkolikleşme olduğu görülmüştür. Çalışanlar işkolik tutumlara sahip olmasalar dahi, zorunlu vatandaşlık davranışı çerçevesinde aşırı ve saplantılı çalışmak durumunda kalmışlardır (Vigoda-Gadot, 2006; Koçak ve Erebak, 2016). Yönetim baskısı veya diğer otoriter öncüllerin yanında belki de iş performanslarının düşük görünmesinin önüne geçmek veya tamamen örgütle özdeşleşmelerinin sonucu olarak çalışanlar, olması gerektiğinden daha fazla çalışıyor ve sürekli işi düşünerek yaşıyorlar (Alkan ve Turgut, 2015). Dolayısıyla çalışanlar, aslında bir tutum olarak işkolikliği sahiplenmiyor olsalar da içlerinde bilişsel bir çelişki barındırarak işkolik davranışlar sergilemeye başlamaktadırlar. Bu çalışmada da işkolik davranışlar, aşırı ve saplantılı çalışma boyutları üzerinden kavramsallaştırılmıştır (Libano vd., 2010). İşkolikliğin pozitif sonuçlarının da olabileceğini öne süren bu çalışma, çalışanın yaşam doyumuna ve işinde kendini ne kadar başarılı gördüğüne etkisinin aydınlatılmasında, işte kendini yetiştirme kavramını bir aracı değişken olarak kullanmıştır. Böylece çalışmanın üç alanda katkı sağlaması amaçlanmıştır: Birincisi, işte kendini yetiştirmenin bireysel esenlik ve iş performansına etkilerini incelemek ve bunun literatüre katkı yapmasını sağlamaktır. İkincisi, işkolikliğin negatif sonuçlarının aksine pozitif sonuçlarının olabileceğini de gösterebilmektir. Literatürdeki çalışmalar, işkolikliğin yaşam doyumunu azalttı̆̆ını öne sürse de (Matuska, 2010; Shimazu vd., 2015) bu araştırmada işkolikliğin yaşam doyumunu nasıl artırabileceği üzerinde durulmuştur. İşkolikliğin kişinin kendini yetiştirmesine, kendi performansına dair algısına etkisi incelenerek işkoliklik literatürüne katkı yapılmıştır. Son olarak, iş hayatının başka boyutlarıyla yaşam doyumu ilişkisi araştırmalarına öncülük edilerek araştırmacıları özendirme gayreti içinde olunmuştur.

\section{Kavramsal çerçeve}

\subsection{Yaşam doyumu}

Yaşam doyumu, insanın en önemli amaçlarından birisi olan mutlulukla ilgili olması açısından gündemde olan konulardan birisidir. Türk Dil Kurumu sözlüğünde doyum, "1. Eldekinden hoşnut olma durumu; 2. bazı istekleri gidermek" olarak ifade edilmektedir. Buradan hareketle yaşam doyumunu genel olarak yaşamımızdan "hoşnut olma" durumu olarak tanımlayabiliriz. Daha açık bir tanımlamayla "yaşam doyumu, bir insanın beklentileriyle (ne istediği), elinde olanların karşılaşttrılmastyla (neye sahip olduğu) elde edilen durum ya da sonuçtur" (Özer ve Karabulut, 2003: 72). Yaşam doyumu, belli boyutlarla sınırlı olmayan, kişinin tüm yaşam boyutlarının etkileşimi sonucu oluşan bir durumu ifade eder. Yukarıdaki tanımdan hareketle "yaşam doyumunun bir bilişsel ve yargısal bir sürece karşıllı geldiğini” (Deiner vd., 1985: 71) söyleyebiliriz. Kişi, kendi yaşamını yine kendisinin belirlemiş olduğu bir standart, beklenti veya ölçüye göre kıyaslar veya tartar. Hayata bakış açısı ve hayattan beklentiler kişiye özgü veya öznel olması nedeniyle kıyaslanacak ölçütün dışarıdan belirlenen bir norm olmadan kişinin kendisi tarafindan belirlemesi, yaşam doyumunun en önemli öğesidir (Deiner vd., 1985). Yaşam doyumu, çalışanın iş dışındaki hayatını da kapsayacak şekilde genel hayat memnuniyetinin bir ifadesi olarak gösterilebilir. Bu anlamda iş, ev gibi hayat alanlarının dışında ama hepsini de kapsayacak şekilde kişinin ne kadar mutlu olduğunu yaşam doyumu gösterecektir. İşkolik çalışanların genel yaşam doyumunun, işkolik olmayanlara göre anlamlı derecede daha az olduğunu gösteren çalışmalar 
bulunmaktadır (Avanzi vd., 2012). Ancak, işkolikliğin yaratıcılık, öğrenme gibi pozitif çıtıları da düşünüldüğünde, bir şekilde hayat tatminini pozitif etkileyeceği düşünülebilir (Baruch, 2011).

\subsection{Algılanan Katkı}

Her birey, içinde bulunduğu çevreye uyum sağlamanın ötesinde, kendi gelişim ihtiyacını gerçekleştirirken çevresine de etki etmek ister (McClelland, 1965). Bu, insanda var olan gelişim ve güç ihtiyacı temelinde gerçekleşmektedir. Ayrıca sosyal psikolojik bir bakış açısıyla bir kimlik inşası ve kişisel izlenim oluşturmak için de kişi sahip olduğu yetenekleri ve başarıları çevresindekilere hissettirmek ve göstermek ister (Bolino, 1999; Grant ve Mayer, 2009). Bu anlamda algılanan katk1 şöyle tanımlanabilir: "Bireyin kendisini, içinde bulunduğu grup veya organizasyonun bir parçası görerek ve onun çıkarına yönelik faaliyetlerde bulunarak ona fayda sağladığına inanmasıdır". Bu tanıma göre yardım etme, başkaları üzerindeki etkiyi görme, problemlerin çözümünde aktif olma, faydalı olmaya çalışma, inisiyatif alma vb. davranışlar, algılanan katkının artmasına yardımcı olacak davranışlar olacaktır.

\section{3. İşkolik Davranışlar}

Artan iş yükü ve uzun çalışma saatleri, çalışanları potansiyel bir işkolik haline getirmektedir. Aslında insanlar sürekli olarak eve iş getirmeye ve akı1lı telefonlar aracıllğıyla maillerini devamlı olarak kontrol edip, cevaplayıp sürekli ulaşılabilir olmaya zorlanmış hissedebilirler. Ancak, bazı çalışanlar, karşı koyamadıkları içsel bir motivasyon sayesinde aşırı derecede çalışmaktadırlar. Bu insanlar işkolik olarak tanımlanabilir (Schaufeli vd., 2008). Schaufeli vd., (2008)'e göre işkoliklik, davranışsal olarak aşırı çalışma ve bilişsel olarak işe saplantılı olma eğilimidir. Bazı araştırmacılar işkolikliğe örgütsel bir bakış açısıyla olumlu bakarken (Machlowitz, 1980; Korn vd., 1987; Naughton, 1987), bazıları ise olumsuz bakmaktadır (Oates, 1971; Schaef ve Fassel, 1988; Porter, 1996; Killinger, 1991). İşkolik olmak bir bağımlılık olsa da üretime sebep olan bir bağımlılıktır (Gini, 1998). İşkolik kişiler, daha fazla projede yer alabilirler ve bu onların daha fazla öğrenmesine sebep olabilir (Shimazu vd., 2010). Tipik bir işkolik, standart bir çalışana göre daha sık iş hakkında konuşur, mesai bitiminin saatler sonrasında bile işi düşünür, daha çok başarı ve görev odaklıdır (McMillan, 2002). En sağlıklı insanlar bile işkolik olabilirler (Fassel, 1990). Bu insanlar hayatlarını işe odaklı olarak yaşamaktadırlar. Dolayısıyla Fassel (1990), işkolikliği modern dünyada ortaya çıkan salgın bir hastalık olarak görmektedir.

\section{4. İşte Kendini Yetiştirme}

İşte kendini yetiştirme kavramı, çalışanın canlılık ve öğrenme hislerini eş zamanlı olarak yaşamasıyla birlikte kişisel bilgisini, becerisini veya tutumlarını geliştirerek işinde başarılı olması anlamına gelmektedir (Spreitzer vd., 2005; Koçak, 2016). Canlılık kişinin enerjik, uyanık, zinde ve coşkulu olma halini belirtirken (Nix vd., 1999), öğrenme kavramı kişinin elde ettiği ve kullandığı bilgi ve becerileri içerir (Elliott ve Dweck, 1988). İşte kendini yetiştirme, çalışanın gelişiminde önemli iki unsur olan duygu ve mantığa hitap eder. Kişi kendisini enerjik ve zinde hissederken bir yandan şevk duyma, hevesli olma, neşeli olma gibi olumlu duygularla bezenir, bir yandan da öğrenmenin gerçekleşmesiyle kişi zihinsel açidan gelişir. Bu sayede kendini yetiştirme, kişisel gelişimin iki boyutu olan bilişsel ve duygusal boyutların her ikisini de içermektedir. Canlılık boyutu ile kişinin haz açısından mutluluğu sağlanarak (hedonic) duygularının düzenlenmesi sağlanırken, öğrenme boyutu ile kişinin mutçu (eudemonic) bilişsel açıdan gelişimi sağlanarak kişinin geliştiği ve güçlendiği söylenebilir (Koçak, 2017). Yapılan araştırmalarda, kendini yetiştirmenin, iş performansını arttırmak için önemli bir mekanizma olduğunu, ayrıca tükenmişliği azalttığı ve sağlığı iyileştirdiğini göstermektedir. Spreitzer vd. (2005) tarafından ortaya konulan modele göre, işte kendini yetiştirmenin en önemli öncülleri kişinin işine odaklanması ve işiyle ilgili yenilikler peşinde olmasıdır. Bu davranışlar sayesinde çalışanların hem canlılık hem de öğrenme düzeylerini arttırabildikleri belirtilmiştir. Aynı modelde ortaya koyulduğu ve geçerliliği test edildiği üzere, işte kendini yetiştiren çalışanların öznel iyi oluşları ve yaşam doyumlarının diğer çalışanlara göre çok daha yüksek olduğu görülmüştür (Porath vd., 2012; Koçak, 2017). 


\subsection{Kavramlar Arası İlişkiler}

Bu çalışmada, kavramsal modelde ortaya koyulan yaşam doyumu ve algılanan katkının öncelleri olarak işkolik davranışlar ve bu iliş̧inin gerçekleşmesini sağlayan bir aracı mekanizma olarak işte kendini yetiştirme kavramı arasındaki ilişkiler test edilmiştir.

Yaşam, işyerinde ve işyeri dışında geçen zamanı kapsar. Çalışma yaşamı, kişinin önemli yaşam alanlarından birisini oluşturduğundan, çalışma hayatının kalitesi ve iş deneyimi birey açısından önemlidir. Çalışanlar, hayat beklentilerin karşılanmasını örgütsel yaşamdan da beklemektedir. İşe yönelik tutumlar ve iş davranışlarının, iş dışı hayatı ve davranışları belirleyen ana faktörler olduğu bilinmektedir (Du vd., 2017). Buradan hareketle, iş doyumunun yaşam doyumunu etkilediği söylenebilir (Iris ve Barrett, 1972; Orpen 1978; Chacko 1983; London vd., 1977). Ayrıca yaşam doyumunu etkileyen unsurlara bakıldığında, özellikle iş-aile çatışmasının ön plana çıktığı görülmektedir (Dursun ve İştar, 2014; Clark vd., 2014). İşkolikliğin de iş-yaşam dengesini bozan en önemli davranışlardan birisi olduğu göz önüne alındığında, işkolik davranışların yaşam doyumu ile ilişkili olması beklenmektedir. Aynı zamanda batı literatürüne zıt olarak, Türkiye'de daha önce yapılan çalışmalarda, çalışanın iş saatlerinden sonra kendisini psikolojik olarak işten uzaklaştırmasının işte kendini yetiştirmesine olumsuz etki ettiği bulunmuştur (Geurts ve Sonnentag, 2006; Koçak, 2017). Dolayısıyla zihnin iş saatleri sonrasında da işi düşünmeyle meşgul olması ve işteki problemlere çözüm araması, yaşanılanların tekrar muhasebe edilmesi vb. işkolik davranışların (aşırı ve saplantılı çalışma) işte kendini yetiştirmeye katkı sağladığı düşünülebilir.

Diğer taraftan algılanan katkı ise çalışanın geçmiş deneyimlerini göz önünde buşundurması ile mümkün olabilir. Özellikle iş yerinde kendisine belirtilen veya kendisinin belirlediği kişisel hedeflerinde başarılı olmanın, ilerlemenin ve kendini yetiştirmenin kişide bir başarı hissi oluşturacağı ve çevresine etki ettiği hissini vermesi beklenen bir olgudur. Çalışanlar kendilerini yetiştirip, daha fazla bilgi ve beceriyle donandıkça yardım etme, bilgi paylaşma gibi diğerkam davranışlarının artması beklenmektedir (Abid vd., 2015). Toplulukçu kültürlere özel olarak, algılanan katkının bir başarı olarak görülebileceği, bu başarma hissinin ise kendini yetiştirmenin akabinde ortaya çıkabileceği bilinmektedir (Singelis, 1995). Özetle, aşırı çalışan ve zihni sürekli işte olan birisinin kendini daha çok yetiştireceğini, bu sayede iş çevresine daha çok katkı yapabileceği düşünülmektedir. Alan yazında yukarıda kısaca açıklamaya çalıştığımız değişkenler arasındaki ilişkileri aracı etkisiyle değerlendiren bir çalışma bulunmamaktadır. $\mathrm{Bu}$ çalışmada da işkolik davranışların yaşam doyumuna ve algılanan katkıya etki edeceği, bu ilişkide çalışanların kendilerini işte yetiştirmelerinin aracı değişken rolü oynayacağı, yani bu ilişkiyi gerçekleştiren mekanizma olduğu, düşünülmüştür. Buna bağlı olarak araştırmamızın modeli aşağıdaki Şekil 1'de gösterildiği gibidir.

Şekil 1. Araştırma Modeli

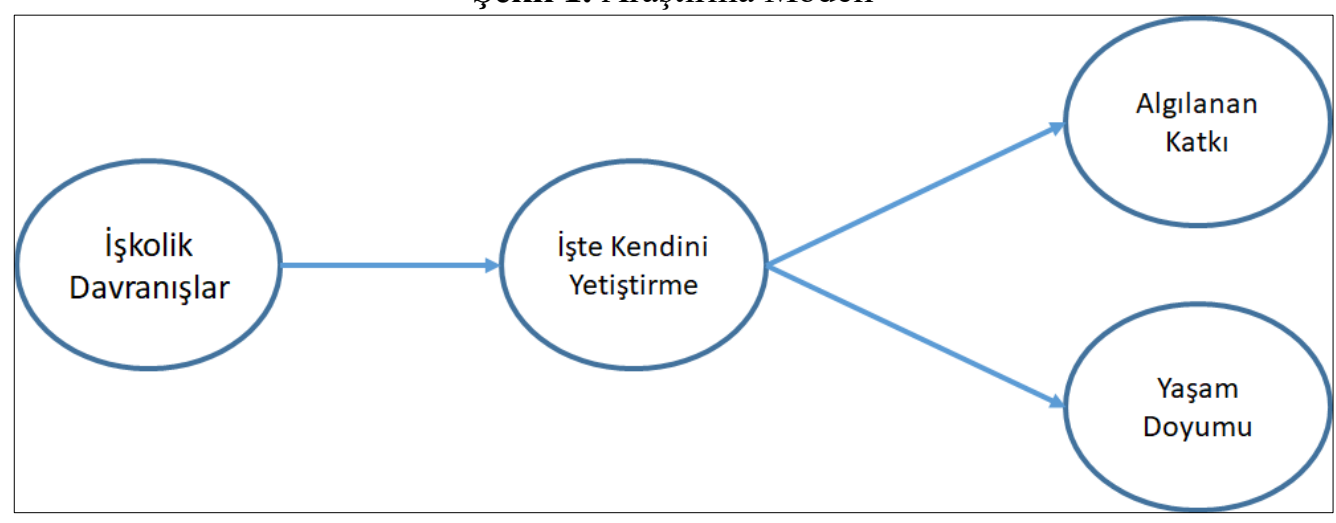

Araştırma modelinden yola çıkarak araştırma hipotezleri aşağıdaki şekilde belirlenmiştir.

$H_{1}$ : İşte kendini yetiştirme, işkolik davranışlar ve yaşam doyumu arasında aracı değişsen görevi görmektedir. 
$\mathrm{H}_{2}$ : İște kendini yetiştirme, işkolik davranışlar ve algılanan katkı arasında aracı değişken görevi görmektedir.

\section{Yöntem}

\subsection{Katılımcılar ve Veri Toplama}

Çalışmada, hipotezlerin test edilmesi amacıyla bir saha araştırması yapılmış ve anket yöntemi kullanılarak veriler toplanmıştır. Kolayda örnekleme yöntemi kullanılarak 256 kişiye ulaşılmıştır. Ancak analizlere uygun olmayan anketlerin dışarda tutulmasının ardından analizler 189 katılımcıya ait anket formlarının cevapları üzerinden yapılmıştır. Araştırmayla ilgili bilgiler hazırlanan anket formunun ön sayfasında yazılı olarak katılımcılara sunulmuştur. Katılımcıların \%55'ini erkekler oluşturuken, $\% 45$ 'i kadınlardan oluşmuştur. Katılımcıların yaş ortalaması 30,90 (ss=8,32) olarak bulunmuş olup, toplam iş hayatı deneyimi ortalaması 8 yıl $(\mathrm{ss}=7,82)$ olarak bulunmuştur. Ayrıca katılımcıların \%43’ünün evli, \%57'sinin ise bekar olduğu görülmüştür.

\section{2. Ölçekler}

Araştırma kapsamında toplanan veriler, algılanan katkı değişkeni dışındaki tüm değişkenler için Türkçe güvenilirliği ve geçerliliği test edilmiş ölçekler ile yapılmıştır. Ölçeklerde 1=Hiç Katılmıyorum'dan 6=Tamamen Katılıyorum'a uzanan 6'lı ölçekler kullanılarak sonuçlar bu değerler üzerinden elde edilmiştir. Ölçekler AMOS yazılımı kullanılarak doğrulayıcı faktör analiziyle test edilmiştir.

İşkolik Davranışlar ölçeği olarak, Loreno vd. (2008) tarafından iki boyutlu olarak geliştirilen 14 maddelik ölçeğin Doğan (2010) tarafından yapılan çevirisi kullanılmıştır. Ölçeğin bileşik güvenilirlik katsayıs1 0,95 , çıkarılan ortalama varyans değeri 0,90 olarak bulunmuştur.

İşte Kendini Yetiştirme ölçeği olarak ise Porath vd. (2012) tarafindan iki boyut ve 10 madde olarak geliştirilen ve Koçak (2016) tarafindan Türkçe'ye çevrilen ancak iki boyutlu ve 8 maddeden oluşan ölçek kullanılmıştır. Ölçeğin bileşik güvenilirlik katsayısı 0,782 , çıkarılan ortalama varyans değeri 0,64 olarak bulunmuştur.

Yaşam Doyumu ölçeği için de Diener vd. (1985) tarafindan geliştirilen ve Köker (1991) tarafından Türkçeye uyarlanan Genel Yaşam Doyumu ölçeği kullanılmıştır. Ölçeğin bileşik güvenilirlik katsayısı 0,863 , çıkarılan ortalama varyans değeri 0,56 olarak bulunmuştur.

Algılanan katkı ölçeği ise yazarlar tarafindan oluşturulmuştur. Bu ölçeğin bileşik güvenilirliği 0,91, ortalama çıkarılan varyans değeri ise 0,72 olarak bulunmuştur. Böylece İşkolik Davranışlar, İște Kendini Yetiştirme, Algılanan Katkı ve Yaşam Doyumu olmak üzere 4 farklı değişken, madde puan ortalamaları alınarak analiz edilmiştir.

\subsection{Analizler}

Çalışmada değişkenler arası ilişkiler ve işte kendini yetiștirmenin aracı değişken etkisi AMOS (Arbuckle, 2010) yazılımı kullanılarak test edilmiştir (Bowen, 2011). Ölçekler üzerinden yapılan doğrulayıcı faktör analizinden sonra elde edilen değişkenlerin madde ortalamaları alınarak değişkenler tanımlandıktan sonra AMOS'ta Yol (Path) Analizi yapılmıştır. Analizin yapılması için AMOS'ta kurulan yol diyagramı aşağıdaki Şekil 2'deki gibidir. 
Şekil 2. Yol (Path) Analizi

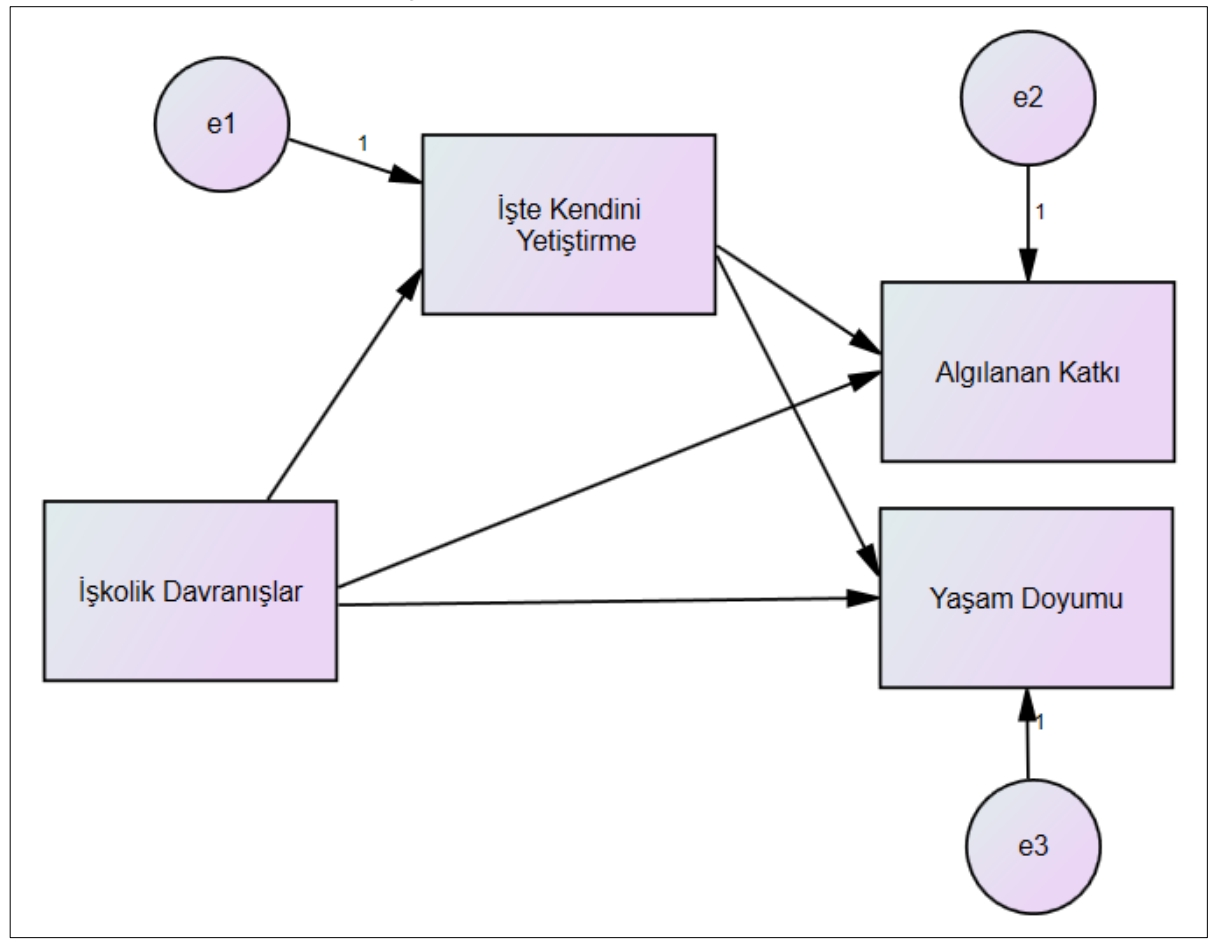

Model uyumu Hu ve Bentler (1999) tarafindan önerilen değerlere göre yapılmıştır. Verilerin hem yap1 geçerliliği hem de güvenilirlik testleri yapılarak değişkenlerin hipotez testine uygun olup olmadığ1 belirlenmiştir. Yapı geçerliliğini test etmek için yakınsak ve ayrım geçerlilikleri test edilmiştir (Fornell ve Larcker, 1981). Yakınsak geçerlilik için doğrulayıcı faktör analizi uygulanmıştır. Ayrım geçerliliği için ise Hair vd. (2012) tarafından belirtildiği gibi her değişkenin ortalama çıkartılan varyans değeri karekökünün, ilgili değişkenin diğer değişkenler ile olan korelasyon katsayısından büyük olup olmadığ1 incelenmiştir. Çok boyutlu olan değişkenler ikincil düzey örtük değişken olarak kurgulanmıştır. Aracı değişken etkisini test etmek için \%95 güven aralığında 2000 örneklemli "bootstrap" yöntemi kullanılmıştır (Preacher ve Hayes, 2004). Model uyumuna ilişkin korelasyon tablosu aşağıdaki Tablo 1'de görülebilir.

Tablo 1. Korelasyon Tablosu

\begin{tabular}{lllll}
\hline Değiş̧kenler & $\mathbf{1}$ & $\mathbf{2}$ & $\mathbf{3}$ & $\mathbf{4}$ \\
\hline 1. Yaşam Doyumu & $\mathbf{0 , 7 8 2}$ & & & \\
2. İşkolik Davranışlar & $0,156^{\dagger}$ & $\mathbf{0 , 9 5 0}$ & & \\
3. Algılanan Katk1 & $0,342^{* * *}$ & $0,279^{* *}$ & $\mathbf{0 , 8 4 9}$ & \\
4. İşte Kendini Yetiştirme & $0,747^{* * *}$ & $0,401^{* * *}$ & $0,654^{* * *}$ & $\mathbf{0 , 8 0 2}$ \\
\hline
\end{tabular}

Kalın yazılmış değerler ilgili satırdaki değişkenin OÇV'sinin kareköküdür. ${ }^{* * *} \mathrm{p}<.001 ; \nmid \mathrm{p}<.10$

\section{Bulgular}

Doğrulayıcı faktör analizi sonuçlarına göre tüm değişkenlerin ölçüm modellerinin uygun olduğu bulunmuştur. Tüm değişkenlerdeki maddelere ait faktör yükleri 0.50 'den büyüktür (Wixom ve Watson, 
2001), ve t-değerleri anlamlıdır (Chin vd., 1997). Bu sonuçlar yakınsak geçerliliğin karşılandığını söylemektedir. Ayrım geçerliliğinin test sonuçları için ise Tablo 1'de verilen kalın yazılmış değerlerin korelasyon katsayıları ile karşılaştırılabilir. Buna göre değişkenlerin ölçümlerinin birbirleriyle örtüşmedikleri görülmüştür. Böylece çalışmada kullanılan ölçeklerle ölçülen kavramların kendi içlerinde doğru bir yapıya sahip oldukları gibi, model içerisindeki diğer değişkenlerle ortak varyans hatası oluşturmayacak kadar ayrılabilmişlerdir (Hair vd., 2012). Araştırma modeli üzerinde herhangi bir değişiklik yapmaya gerek kalmadan elde edilen ölçüm modeli uyum değerleri $x^{2}$ : 372,085 df:242 CFI: 0,954, TLI:0,967, RMSEA:0,053, SRMR: 0,060 olarak bulunmuştur. Ayrıca ortak yöntem varyansı da kontrol edilmiş, Harman Tek Faktör testinde tek faktörün \%32'lik bir varyans açıkladığı görülmüştür. Tüm bu sonuçlara göre ilgili değişkenlerinin kavramsal olarak kurgulandığı şekilde AMOS'ta kurulan modelde kullanılmasına geçilmiştir. Hipotezin testi için oluşturulan modelde uyum değerlerinin yanısıra standardize edilmiş katsayılar, anlamlılık düzeyleri ve endojen değişkenlerin $\mathrm{R}^{2}$ leri ile değerlendirilmiştir.

Analizler sonucunda modelin uyum değerleri x2:377,343 df:243 CFI: 0,952, TLI:0,946, RMSEA:0,054, SRMR: 0,060 olarak bulunmuştur. Bu değerlere göre modelin uyumlu olduğu ve ilişkilerin incelenebilir olduğu düşünülmüştür (Hu ve Bentler, 1999). Aracı değişken analizi için yapılan bootstrapping yöntemiyle elde edilen sonuçlar, işte kendini yetiştirmenin işkolik davranışlar ile hem genel yaşam doyumu $(\gamma=0,30 ; \mathrm{SE}=0,085 ; \% 95 \mathrm{CI}=0,069 ; 0,406)$ hem de algilanan katk1 $(\gamma=0,23 ; \mathrm{SE}=0,105 ; \% 95$ $\mathrm{CI}=0,087 ; 0,500)$ arasında aracı değişken etkisi gösterdiğini ortaya koymaktadır. Buna göre $\mathrm{H}_{1}$ ve $\mathrm{H}_{2}$ desteklenmiştir. Kurulan model ile çalışmanın bağımlı değişkeni olan genel yaşam doyumunun, algılanan katkının ve işte kendini yetiştirmenin açıklanan varyans oranları sırasıyla $\% 53, \% 37$ ve $\% 15$ olarak bulunmuştur. Bu değerler Falk ve Miller (1992) tarafindan tavsiye edilen \%10'un oldukça üzerindedir.

\section{Sonuç}

Bu çalışma sonuçlarına bakıldığında kişinin işkolik davranışlar sergilemesinin, yani aşırı çalışması ve sürekli işleri düşünmesinin kendini işte yetiştirmesine olumlu etki ettiği ve bunun yaşamına ait olumlu yargılara önemli ölçüde katkı yaptığı görülmektedir. Araştırmada, çalışanların işkolik davranışları ve yaşam doyumu arası direkt ilişkide olumsuz ancak anlamsız bir ilişki bulunmuş, kendini yetiştirme üzerinden ise pozitif ve anlamlı bir dolaylı etki bulunmuştur. İşkolik davranışlar ile algılanan katkı arasında ise anlamsız ve sıfıra yakın bir direkt etki bulunmuşken, kendini yetiştirme üzerinden anlamlı ve güçlü bir dolaylı etki bulunmuştur. Buna göre, işkolik davranışların çalışanların kendilerini yetiştirmelerine hizmet ettiği, bu sayede çalışanların kendilerini daha faydalı gördükleri ve aynı zamanda yaşam doyumlarının da arttığı görülmüştür.

Çalışmada işkolik davranışlar ile yaşam doyumu arasındaki olumlu korelasyonla birlikte yol analizindeki olumsuz ancak anlamsız olan direkt yol bir tarafta, işte kendini yetiştirmenin sağladığı dolaylı yol ise diğer tarafta değerlendirildiğinde, direkt etki ile dolaylı etkinin işaretleri birbirinden farklıdır. Modelin bu kısmında her ne kadar Baron ve Kenny'nin (1986) önerdiği aracı değişken testi sürecine uyuluyor olsa da bir rekabetçi aracı değişken durumunun olduğu görülmüştür (Hayes ve Preacher, 2004). Bu durum, bu işkolik davranışlar ve yaşam doyumu ilişkisinin nasıl gerçekleştiğini anlama noktasında başka ara değişkenlere de gerek olduğunu göstermektedir. Diğer taraftan algılanan katkı bağımsız değişkeni açısından, işte kendini yetiştirmenin tam bir aracı değişken görevi gördüğü söylenmelidir. Buna göre aşırı ve saplantılı çalışmanın çalışanlar için işte kendilerini yetiştirmeyi sağladığı ve bu sayede çevrelerine daha çok katkı yaptıkları görülmüştür.

İleride yapılacak çalışmalar için işkolik davranışlar için iş-aile dengesi gibi değişkenlerin aracı değişken olarak sınanması önerilebilir. Yine aynı şekilde kişi örnekleme yöntemi ve örneklem azlığı, ölçeklerin tamamının aynı kişiden toplanması gibi kısıtlar nedeniyle çalışmanın genellenebilme özelliği zayıftır. 


\section{BEYANLAR}

Hakem Değerlendirmesi: Dış bağımsız.

Çıkar Çatışması: Yazarlar arasında çıkar çatışması yoktur.

Finansal Destek: Yazarlar bu çalışma için finansal destek almamıştır.

Katk1 Payı Oranı: Yarı yarıya (\%50/\%50)'dir. 


\section{KAYNAKÇA}

Abid, G., Zahra, I., \& Ahmed, A. (2015). Mediated Mechanism of Thriving at Work between Perceived Organization Support, Innovative Work Behavior and Turnover Intention. Pakistan Journal of Commerce and Social Sciences, 9(3), 982-998.

Alkan, S. E., \& Turgut, T. (2015). A research about the relationship of psychological safety and organizational politics perception with compulsory citizenship behavior and the pressures behind compulsory citizenship behavior. Research journal of Business and Management, 2(2), 185-203.

Arbuckle, J. L. (2010). IBM SPSS Amos 19 user’s guide. Crawfordville, FL: Amos Development Corporation, 635.

Avanzi, L., van Dick, R., Fraccaroli, F., \& Sarchielli, G. (2012). The downside of organizational identification: Relations between identification, workaholism and well-being. Work \& Stress, 26(3), 289-307.

Baron, R. M., \& Kenny, D. A. (1986). The moderator-mediator variable distinction in social psychological research: Conceptual, strategic, and statistical considerations. Journal of personality and social psychology, 51(6), 1173.

Baruch, Y. (2011). )e Positive Wellbeing Aspects of Workaholism in Cross Cultural Perspective the Chocoholism Metaphor. Career Development International, 16(6), 572-591. doi:10.1108/13620431111178335

Bolino, M. C. (1999). Citizenship and impression management: Good soldiers or good actors?. Academy of Management Review, 24(1), 82-98.

Bowen, N. K., \& Guo, S. (2011). Structural equation modeling. Oxford University Press.

Chacko, T. I. (1983). Job and life satisfactions: A causal analysis of their relationships. Academy of Management Journal, 26(1), 163-169.

Chin, W. W., Gopal, A., \& Salisbury, W. D. (1997). Advancing the theory of adaptive structuration: The development of a scale to measure faithfulness of appropriation. Information systems research, 8(4), 342-367.

Clark, M. A., Michel, J. S., Stevens, G. W., Howell, J. W., \& Scruggs, R. S. (2014). Workaholism, work engagement and work-home outcomes: Exploring the mediating role of positive and negative emotions. Stress and Health, 30(4), 287-300.

Deiner, E. (2000). Subjective well-being: The science of happiness and a proposal for a national index. American Psychologist, Vol 55(1), 34-43.

Diener, E. D., Emmons, R. A., Larsen, R. J. ve Griffin, S. (1985). The satisfaction with life scale. Journal of personality assessment, 49(1), 71-75.

Diener, E., Sapyta, J. J., \& Suh, E. (1998). Subjective well-being is essential to well-being. Psychological Inquiry, 9, 33-37.

Du, D., Derks, D., Bakker, A. B., \& Lu, C. Q. (2017). Does homesickness undermine the potential of job resources? A perspective from the work-home resources model. Journal of Organizational Behavior.

Dursun, S. ve İştar, E. (2014). Kadın Çalışanların Yaşamış Oldukları İş Aile Yaşamı Çatışmasının İş Ve Yaşam Doyumu Üzerine Etkisi. Atatürk Üniversitesi İktisadi ve İdari Bilimler Dergisi, 28(3), 127-137.

Elliott, E. S., \& Dweck, C. S. (1988). Goals: An approach to motivation and achievement. Journal of personality and social psychology, 54(1), 5.

Erdoğan, B., Bauer, T. N., Truxillo, D. M., \& Mansfield, L. R. (2012). Whistle while you work: A review of the life satisfaction literature. Journal of Management, 38(4), 1038-1083.

Falk, R. F., \& Miller, N. B. (1992). A primer for soft modeling. University of Akron Press.

Fassel, D. (1990), Working Ourselves to Death: The High Cost of Workaholism, the Rewards of Recovery, Harper San Francisco.

Fornell, C., \& Larcker, D. F. (1981). Evaluating structural equation models with unobservable variables and measurement error. Journal of marketing research, 39-50. 
Geurts, S. A., \& Sonnentag, S. (2006). Recovery as an explanatory mechanism in the relation between acute stress reactions and chronic health impairment. Scandinavian journal of work, environment \& health, 482-492.

Gini, A. L. (1998), "Working Ourselves to Death: Workaholism, Stress, And Fatigue”, Business and Society Review, 100(1), pp. 45-56.

Grant, A. (2014). Give and take: Why helping others drives our success. Penguin.

Grant, A. M., \& Mayer, D. M. (2009). Good soldiers and good actors: prosocial and impression management motives as interactive predictors of affiliative citizenship behaviors. Journal of Applied Psychology, 94(4), 900.

Hair, J. F., Sarstedt, M., Pieper, T. M., \& Ringle, C. M. (2012). The use of partial least squares structural equation modeling in strategic management research: a review of past practices and recommendations for future applications. Long range planning, 45(5), 320-340.

Hochschild, A. R. (1997). When work becomes home and home becomes work. California Management Review, 39(4), 79-97.

Hu, L. T., \& Bentler, P. M. (1999). Cutoff criteria for fit indexes in covariance structure analysis: Conventional criteria versus new alternatives. Structural equation modeling: a multidisciplinary journal, 6(1), 1-55.

Iris, B. ve Barrett, G. V. (1972). Some relations between job and life satisfaction and job importance. Journal of applied Psychology, 56(4), 301-304.

Killinger, B. (1991), Workaholics: the Respectable Addicts, Simon and Schuster, New York, NY.

Koçak, Ö. E. (2016). How to Enable Thriving at Work through Organizational Trust. International Journal of Research in Business and Social Science, 5(4), 40.

Koçak, Ö.E. (2017) How Employees Thrive at Work? Importance of Relationship Quality, Person-Job Fit, and Recovery Experiences After Work Hours. Unpublished Doctoral Thesis. Marmara University. İstanbul.

Koçak, Ö.E., Erebak, S. (2017) İş Amaçlı Akıllı Telefon Kullanımı ve İş-Ev Dengesi İlişkisi: İşkolikliğin Aracı Değişken Etkisi. İş, Güç Endüstri İlişkileri ve İnsan Kaynakları Dergisi (İncelemede)

Korn, E. R., Pratt, G. J. ve Lambrou, P. T. (1987), Hyper-Performance: The AIM Strategy for Releasing Your Business Potential, John Wiley ve Sons.

Libano, M. D., Salanova, M., \& Schaufeli, W. (2010). Validity of a brief workaholism scale. Psicothema-Revista de Psicologia, 22(1), 143-150.

London, M., Crandall, R. ve Seals, G. W. (1977). The contribution of job and leisure satisfaction to quality of life. Journal of Applied Psychology, 62(3), 328-334.

Machlowitz, M. (1980), Workaholics, Living with Them, Working with Them, Addison Wesley Publishing Company.

Matuska, K. M. (2010). Workaholism, life balance, and well-being: a comparative analysis. Journal of Occupational Science, 17(2), 104-111.

McClelland, D. C. (1965). Toward a theory of motive acquisition. American psychologist, 20(5), 321.

McMillan, L. H. W. (2002). Workaholism: How Does it Impact on People's Lives?.

Naughton, T. J. (1987). A conceptual view of workaholism and implications for career counseling and research. The Career Development Quarterly, 35(3), 180-187.

Nix, G. A., Ryan, R. M., Manly, J. B., \& Deci, E. L. (1999). Revitalization through self-regulation: The effects of autonomous and controlled motivation on happiness and vitality. Journal of Experimental Social Psychology, 35(3), 266-284

Oates, W. E. (1971), Confessions of a Workaholic: The Facts about Work Addiction, World Publishing Company.

Orpen, C. (1978). Work and Nonwork Satisfaction: A Causal-Correlational Analysis. Journal of Applied Psychology, 63(4), 530-532.

Özer, M. ve Karabulut, Ö. Ö. (2003). Life satisfaction in the elderly. Yaşl1larda yaşam doyumu. Geriatri, 6(2), $72-$ 74.

Paterson, T. A., Luthans, F., \& Jeung, W. (2014). Thriving at work: Impact of psychological capital and supervisor support. Journal of Organizational Behavior, 35(3), 434-446. 
Peterson, C., Park, N., \& Seligman, M. E. (2005). Orientations to happiness and life satisfaction: The full life versus the empty life. Journal of happiness studies, 6(1), 25-41.

Porath, C., Spreitzer, G., Gibson, C., \& Garnett, F. G. (2012). Thriving at work: Toward its measurement, construct validation, and theoretical refinement. Journal of Organizational Behavior, 33(2), 250-275.

Porter, G. (1996), “Organizational Impact of Workaholism: Suggestions for Researching the Negative Outcomes of Excessive Work”, Journal of Occupational Health Psychology, 1(1), pp. 70.

Preacher, K. J., \& Hayes, A. F. (2004). SPSS and SAS procedures for estimating indirect effects in simple mediation models. Behavior research methods, 36(4), 717-731.

Schaef, A. W. ve Fassel, D. (1988), The Addictive Organization, Harper ve Row Publishers.

Schaufeli, W. B., Taris, T. W., \& Bakker, A. B. (2008). It takes two to tango. Workaholism is working excessively and working compulsively. The long work hours culture. Causes, consequences and choices, 203-226.

Schaufeli, W. B., Taris, T. W., \& Van Rhenen, W. (2008). Workaholism, burnout, and work engagement: three of a kind or three different kinds of employee well-being?. Applied Psychology, 57(2), 173-203.

Shimazu, A., Schaufeli, W. B. ve Taris, T. W. (2010), “How Does Workaholism Affect Worker Health And Performance? The Mediating Role of Coping”, International Journal of Behavioral Medicine, 17(2), pp. 154-160.

Singelis, T. M., \& Brown, W. J. (1995). Culture, self, and collectivist communication linking culture to individual behavior. Human communication research, 21(3), 354-389.

Singelis, T. M., Bond, M. H., Sharkey, W. F., \& Lai, C. S. Y. (1999). Unpackaging culture’s influence on selfesteem and embarrassability: The role of self-construals. Journal of Cross-Cultural Psychology, 30(3), $315-341$.

Sonenshein, S., Dutton, J. E., Grant, A. M., Spreitzer, G. M., \& Sutcliffe, K. M. (2013). Growing at work: Employees' interpretations of progressive self-change in organizations. Organization Science, 24(2), 552-570.

Spreitzer, G. M., \& Sutcliffe, K. M. (2007). Thriving in organizations. Positive organizational behavior, 74-85.

Spreitzer, G., Sutcliffe, K., Dutton, J., Sonenshein, S., \& Grant, A. M. (2005). A socially embedded model of thriving at work. Organization science, 16(5), 537-549.

Tokat, L. (2006). Farabi felsefesinde mutluluğun araştırılması. Dinbilimleri Akademik Araştırma Dergisi, 6(2), 133-157.

VIGODA-GADOT, E. R. A. N. (2006). Compulsory citizenship behavior: Theorizing some dark sides of the good soldier syndrome in organizations. Journal for the Theory of Social Behaviour, 36(1), 77-93.

Wixom, B. H., \& Watson, H. J. (2001). An empirical investigation of the factors affecting data warehousing success. MIS quarterly, 17-41. 